\title{
Efficacy and Compliance of Oral Iron Poly-Maltose Complex versus Oral Ferrous Sulfate in the Treatment of Iron Deficiency Anemia in Pregnant Women
}

\author{
Mohamed A. Elsenity, Rehab M. Abdelrahman*, Ayman M. Abdelkader, Maha M. Kamel \\ Department of Obstetrics and Gynecology, University of Ain Shams College of Medicine, Maternity Hospital, Cairo, Egypt \\ Email: ${ }^{\star}$ rehababdulrahman.rm@gmail.com
}

How to cite this paper: Elsenity, M.A., Abdelrahman, R.M., Abdelkader, A.M. and Kamel, M.M. (2018) Efficacy and Compliance of Oral Iron Poly-Maltose Complex versus Oral Ferrous Sulfate in the Treatment of Iron Deficiency Anemia in Pregnant Women. Open Journal of Obstetrics and Gynecology, 8, 1084-1093

https://doi.org/10.4236/ojog.2018.811109

Received: September 6, 2018

Accepted: September 26, 2018

Published: September 29, 2018

Copyright $\odot 2018$ by authors and Scientific Research Publishing Inc. This work is licensed under the Creative Commons Attribution International License (CC BY 4.0).

http://creativecommons.org/licenses/by/4.0/

\section{(c) (i) Open Access}

\begin{abstract}
Objective: To compare the efficacy and compliance of the conventional therapy of iron deficiency anemia (ferrous sulfate) with the new forms of therapy chewable iron tablets: (iron polymaltose complex) in the treatment of iron deficiency anemia in pregnant women. Methods: This Randomized Control Trial study included 290 pregnant women with iron deficiency anemia, and they were randomly allocated to a control group who received ferrous sulfate capsules for two months and study group who received iron polymaltose complex chewable tablets for two months. Complete Blood Picture (hemoglobin level and hematocrit level) and Serum ferritin level were done after four and eight weeks to determine the efficacy. In addition, any complains or side effects had been reported to assess the tolerability of the drugs. Two-factor repeated-measures analysis of variance (ANOVA) was used to compare the change in hemoglobin and serum ferritin levels in both groups. Results: There was no statistical significant difference between the two research groups as regards baseline hemoglobin, and at week 4 from onset of treatment ( $\mathrm{p}$ values $=0.990,0.112$, consecutively). However, there was statistical significant difference on week 8 of continuous drug intake in both groups in which the iron poly maltose complex research group had significantly higher hemoglobin levels ( $\mathrm{p}$ value $=0.006$ ). Conclusion: The results of the study showed oral iron polymaltose complex increases Hemoglobin and serum ferritin levels more than oral ferrous sulfate and produces less adverse effects than ferrous sulfate.
\end{abstract}

\section{Keywords}

Iron Deficiency Anemia, Iron Poly-Maltose Complex, Ferrous Sulfate 


\section{Introduction}

The World Health Organization (WHO) defines anemia in pregnancy as a hemoglobin $(\mathrm{Hb})$ concentration of $<11 \mathrm{~g} / \mathrm{dl}$. Iron deficiency anemia is the most common type of anemia in pregnancy. The iron content of the body is normally kept constant by regulating the amount absorbed to balance the amount lost [1]. The WHO estimates that $58 \%$ of pregnant women in developing countries are anemic mainly because of iron deficiency [2]. Almost all cases of iron deficiency anemia respond readily to treatment with iron supplementation, patients do not always respond adequately to oral iron therapy because of noncompliance due to side effects. Gastrointestinal disturbances characterized by colicky pain, nausea, vomiting, diarrhea, and gastric distress occur in about $6 \%-12 \%$ of patients taking iron preparations [3]. The most common iron salt used for oral administration is ferrous sulfate, it is known to produce intestinal side effects (nausea, vomiting, constipation, bloating) in many users [4]. Iron Polymaltose Complex (IPC), a combination of ferric iron with maltol (a food additive), was developed as a molecule that is soluble at neutral $\mathrm{pH}$ and is not chelated by other substances [5].

\section{Materials and Methods}

\subsection{Study Population}

This Randomized Control Trial study was performed at Ain Shams University Maternity Hospital outpatient clinic included 290 pregnant women with iron deficiency anemia. Inclusion criteria included page 20 - 35 years; Hb 7 - 11 g/dl (mild to moderate anemia); and Serum ferritin $<12 \mathrm{mcg} / \mathrm{L}$. Patients with a history of anemia due to any other causes such as chronic blood loss, hemolytic anemia, and thalassemia were excluded from the study. The institutional review board approved this study. The participants were counseled and after they agreed, they were included into the study. A total of 290 patients were included in the study distributed in two groups: Group A-control group- $($ no $=145)$ received ferrous sulfate $60 \mathrm{mg}$ capsulestds (Ferrofol, EGYPTIAN INT. PHARMACEUTICAL INDUSTRIES CO. (E.I.P.I.CO.)-Egypt) for two months. Group b $($ no $=145)$ received iron polymaltose complex (Ferose F, SPIMACO, Saudi Arabia) chewable tablets for two months. All the patients had taken their allocated treatment regularly with same dietetic regime for two months after diagnosis of iron deficiency anemia with Complete Blood Picture (hemoglobin level and hematocrit level) and Serum ferritin level and to be followed up after four and eight weeks to determine the efficacy. Also, any complains or side effects had been reported to assess the tolerability of the drugs.

\subsection{Randomization}

All patients were distributed into two groups with each group allocated to have one drug according to the randomization table. 


\subsection{Allocation and Concealment}

290 opaque envelopes were numbered serially and in each envelope the corresponding letter which donate the allocated group were put according to randomization table, then all envelopes were closed and put in one box. When the first patient arrived the first envelope was opened and the women were allocated according to the letter inside.

\subsection{Statistical Analysis}

Data were analyzed using IBM@ SPSS $\odot$ Statistics version 23 (IBM@ Corp., Armonk, NY, USA) and MedCalc@ version 15 (MedCalc@ Software bvba, Ostend, Belgium).The Shapiro-Wilk test was used to examine the normality of numerical data distribution. Normally distributed numerical variables were presented as mean \pm SD and inter-group differences were compared using the unpaired test. Categorical variables were presented as number (\%) and intergroup differences were compared using Fisher's exact test (for nominal data) or the chi-squared test for trend (for ordinal data). Two-factor repeated-measures analysis of variance (ANOVA) was used to compare the change in hemoglobin and serum ferritin levels in both groups. The Greenhaus-Geisser method was used to correct the degree of freedom as the assumption of sphericity was not fulfilled. $\mathrm{P}$-value $<0.05$ was considered statistically significant.

\section{Results}

This study was conducted on 290 pregnant women with iron deficiency anemia: Ferrous sulfate group (control group) mean age of $31.8 \pm 5.8$ and Iron polymaltose complex group $31.3 \pm 5.4$.

Table 1 shows that there was no significant difference between the two groups on week 0 , and week 4 . However, there was significant difference on week 8 of continuous drug intake in both groups.

Figure 1 shows that there was a steady rise in hemoglobin levels in both study groups, but the rise was more obvious late in the study in group B (IPC group).

Table 2 shows the difference of serum ferritin level between the two groups showing no significant difference between both groups on week 0,4 , or 8 .

Figure 2 shows the difference of rise of serum ferritin level in both groups, showing nearly similar rise in both groups throughout the study.

Table 1. Comparison of hemoglobin level in both study groups.

\begin{tabular}{cccccc}
\hline Variable & $\begin{array}{c}\text { Ferrous sulfate } \\
(\mathbf{n}=145)\end{array}$ & $\begin{array}{c}\text { Iron polymaltose } \\
\text { complex }(\mathbf{n}=145)\end{array}$ & T & Df & p-value \\
\hline $\begin{array}{c}\text { Baseline hemoglobin } \\
(\mathrm{g} / \mathrm{dl})\end{array}$ & $9.3 \pm 0.9$ & $9.4 \pm 0.9$ & 0.013 & 288 & 0.990 \\
$\begin{array}{c}\text { Hemoglobin at } 4 \\
\text { weeks (g/dl) }\end{array}$ & $10.4 \pm 0.9$ & $10.5 \pm 0.8$ & -1.595 & 288 & 0.112 \\
$\begin{array}{c}\text { Hemoglobin at } 8 \\
\text { weeks }(\mathrm{g} / \mathrm{dl})\end{array}$ & $11.3 \pm 0.8$ & $11.5 \pm 0.7$ & -2.786 & 288 & 0.006 \\
\hline
\end{tabular}


Table 2. Comparison of serum ferritin level in both study groups.

\begin{tabular}{cccccc}
\hline Variable & $\begin{array}{c}\text { Ferrous } \\
\text { sulfate }(\mathbf{n}=145)\end{array}$ & $\begin{array}{c}\text { Iron polymaltose } \\
\text { complex }(\mathbf{n = 1 4 5 )}\end{array}$ & $\mathbf{t}$ & $\mathrm{df}$ & $\mathrm{p}$-value \\
\hline Baseline ferritin $(\mu \mathrm{g} / \mathrm{l})$ & $9.4 \pm 1.2$ & $9.5 \pm 1.2$ & -0.644 & 288 & 0.520 \\
Ferritin at 4 weeks $(\mu \mathrm{g} / \mathrm{l})$ & $9.8 \pm 1.2$ & $9.9 \pm 1.2$ & -0.956 & 288 & 0.340 \\
Ferritin at 8 weeks $(\mu \mathrm{g} / \mathrm{l})$ & $10.5 \pm 1.5$ & $10.6 \pm 1.3$ & -0.529 & 288 & 0.597 \\
\hline
\end{tabular}

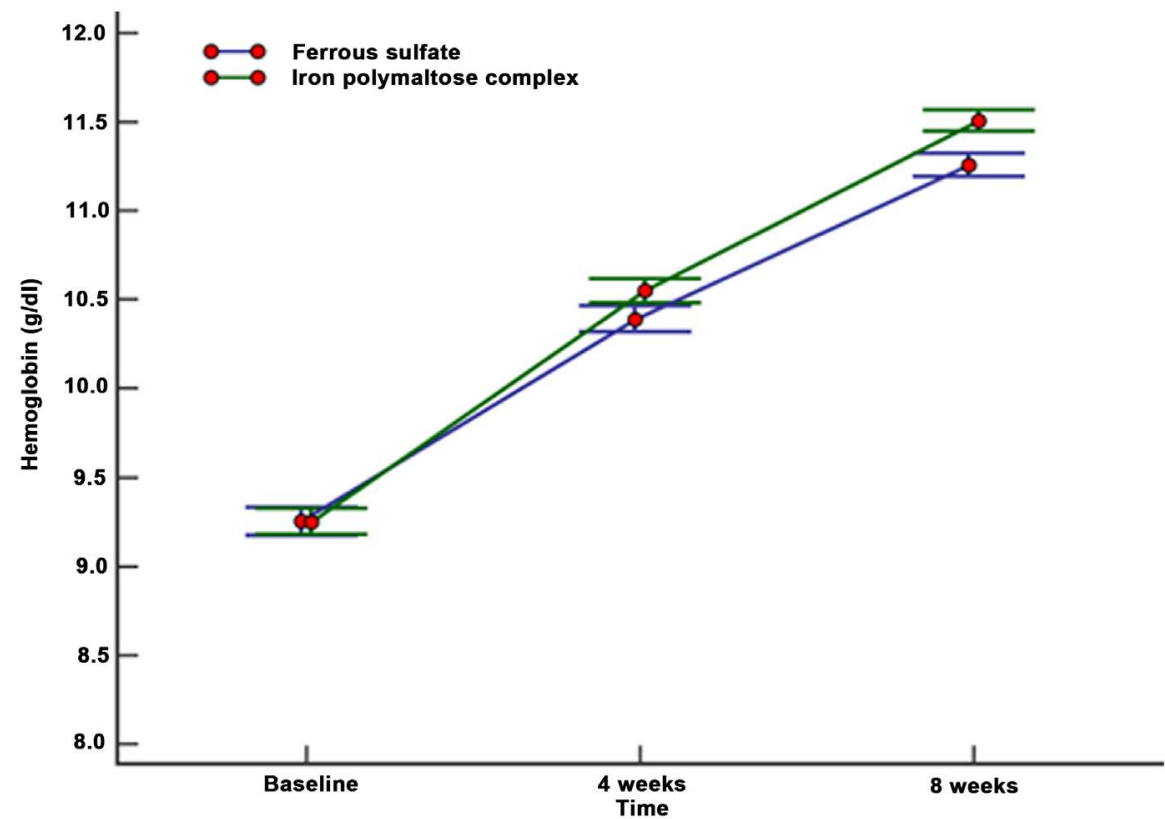

Figure 1. Mean hemoglobin level in both study groups. Error bars represent the standard error of the mean (SEM).

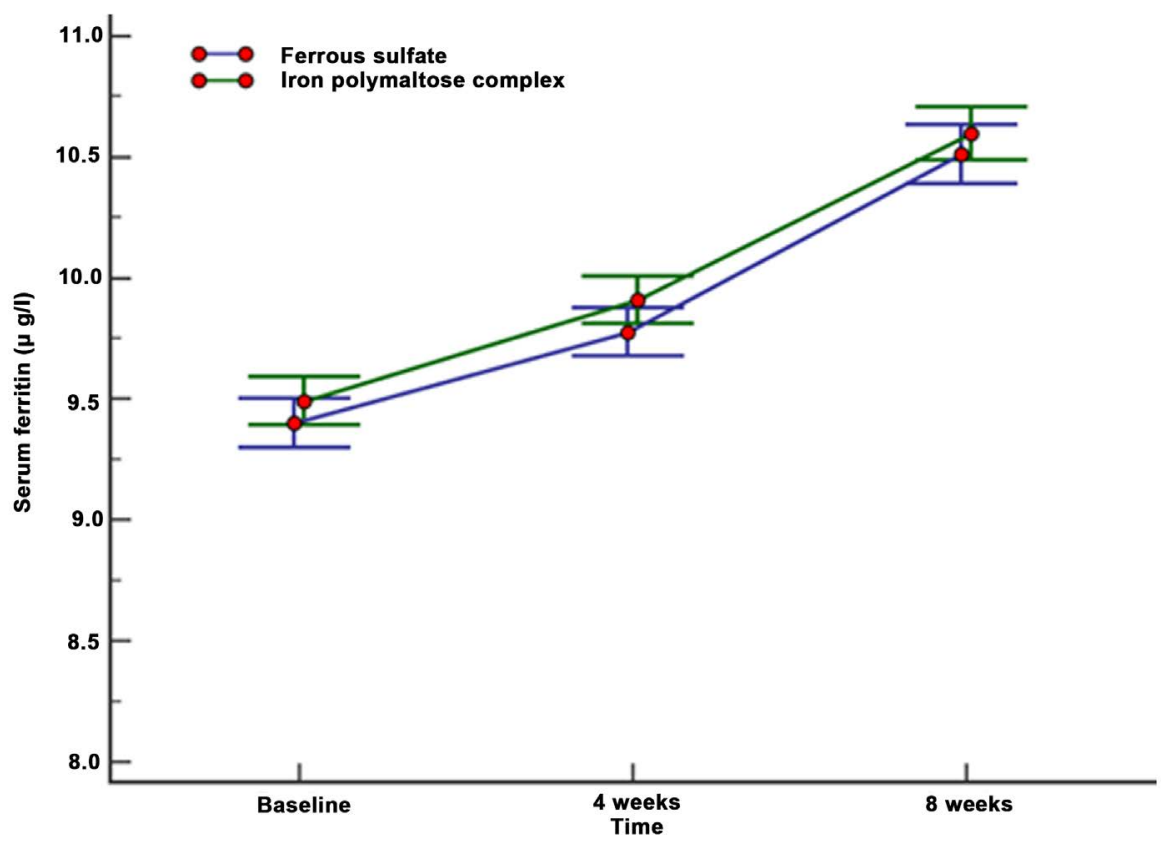

Figure 2. Mean serum ferritin level in both study groups. Error bars represent the standard error of the mean (SEM). 
A repeated-measures ANOVA was conducted to examine the effect of time and treatment on the change in hemoglobin level. The assumption of sphericity could not be assumed (Greenhouse-Geisser epsilon, 0.662; Huynh-Feldtepsiln, 0.664). So, the Greenhouse-Geisser's correction was used to correct the degree of freedom (df). The test of between-subjects effects showed that there was no statistically significant difference between the two groups $[\mathrm{F}(1,288)=1.99$; $\mathrm{p}$-value $=$ 0.159]. The test of within-subjects effects showed that there was a significant effect of time on hemoglobin $[\mathrm{F}(1.324,381.33)=5292.79$; $\mathrm{p}$-value $<0.001]$. Moreover, there was a statistically significant interaction between time and treatment $[\mathrm{F}(1.324,381.33)=18.86$; $\mathrm{p}$-value $<0.001]$ (Table 3).

A repeated-measures ANOVA was conducted to examine the effect of time and treatment on the change in serum ferritin level. The assumption of sphericity could not be assumed (Greenhouse-Geisser epsilon, 0.540; Huynh-Feldtepsiln, 0.541). So, the Greenhouse-Geisser's correction was used to correct the degree of freedom (df). The test of between-subjects effects showed that there was no statistically significant difference between the two groups $[F(1,288)=0.52$; $p$-value $=0.473]$. The test of within-subjects effects showed that there was a significant effect of time on serum ferritin level $[\mathrm{F}(1.08,311.099)=676.41$; p-value $<0.001]$. However, there was no statistically significant interaction between time and treatment $[\mathrm{F}(1.08,311.099)=0.350 ; \mathrm{p}$-value $=0.571]($ Table 4$)$.

Figure 3 shows the incidence of adverse effects in both groups, showing less incidence of side effects such as: GI upset, vomiting, and constipation in group B (iron polymaltose complex).

Table 5 shows significant difference between both groups in their side effects such as: GI upset, vomiting, and constipation.

Table 3. Repeated measure analysis of variance for the change in hemoglobin.

\begin{tabular}{|c|c|c|c|c|c|}
\hline \multicolumn{6}{|c|}{ Test of sphericity } \\
\hline Method & Epsilon & & & & \\
\hline Greenhouse-Geisser & 0.662 & & & & \\
\hline Huynh-Feldt & 0.664 & & & & \\
\hline \multicolumn{6}{|c|}{ Test of Between-Subjects Effects } \\
\hline Source of variation & Sum of Squares & $\mathrm{DF}$ & Mean Square & $\mathrm{F}$ & p-value \\
\hline Groups (group) & 4.015 & 1 & 4.015 & 1.99 & 0.159 \\
\hline Residual & 580.495 & 288 & 2.016 & & \\
\hline \multicolumn{6}{|c|}{ Test of Within-Subjects Effects } \\
\hline Source of variation & Sum of Squares & $\mathrm{DF}$ & Mean Square & $\mathrm{F}$ & p-value \\
\hline Factor & 663.001 & 1.324 & 500.733 & 5292.79 & $<0.001$ \\
\hline $\begin{array}{c}\text { Group } \times \text { Factor } \\
\text { interaction }\end{array}$ & 2.363 & 1.324 & 1.784 & 18.86 & $<0.001$ \\
\hline Residual & 36.076 & 381.33 & 0.0946 & & \\
\hline
\end{tabular}


Table 4. Repeated measure analysis of variance for the change in serum ferritin.

\begin{tabular}{cccccc}
\hline \multicolumn{5}{c}{ Test of sphericity } \\
\hline Method & Epsilon & & \\
\hline $\begin{array}{c}\text { Greenhouse-Geisser } \\
\text { Huynh-Feldt }\end{array}$ & 0.540 & 0.541 & & & \\
\hline \multicolumn{6}{c}{ Test of Between-Subjects Effects } \\
\hline Source of variation & Sum of Squares & DF & Mean Square & F & p-value \\
\hline $\begin{array}{c}\text { Groups (group) } \\
\text { Residual }\end{array}$ & 2.338 & 1 & 2.338 & 0.52 & 0.473 \\
\hline \multicolumn{7}{c}{ Test of Within-Subjects Effects } & & \\
\hline Source of variation & Sum of Squares & DF & Mean Square & F & p-value \\
\hline $\begin{array}{c}\text { Factor } \\
\text { Group } \times \text { Factor } \\
\text { interaction } \\
\text { Residual }\end{array}$ & 183.123 & 1.08 & 169.526 & 676.41 & $<0.001$ \\
\hline
\end{tabular}

Table 5. Risk analysis for the incidence of adverse effects in both groups.

\begin{tabular}{ccccccc}
\hline $\begin{array}{c}\text { Adverse } \\
\text { outcome }\end{array}$ & $\begin{array}{c}\text { Relative risk } \\
\text { (RR) }\end{array}$ & $\begin{array}{c}95 \% \text { CI for } \\
\text { RR }\end{array}$ & $\begin{array}{c}\text { Z } \\
\text { Score* }\end{array}$ & p-value & $\begin{array}{c}\text { Number needed } \\
\text { to treat (NNT) }\end{array}$ & $\begin{array}{c}95 \% \text { CI } \\
\text { for NNT }\end{array}$ \\
\hline GI upset & 0.43 & 0.33 to 0.56 & 6.142 & $<0.0001$ & 2.5 & 1.98 to 3.4 \\
Vomiting & 0.57 & 0.38 to 0.84 & 2.812 & $\mathbf{0 . 0 0 5}$ & 6.6 & 4.0 to 19.9 \\
Constipation & 0.61 & 0.49 to 0.76 & 4.411 & $\mathbf{0 . 0 0 0 1}$ & 3.7 & 2.6 to 6.3 \\
\hline
\end{tabular}

${ }^{*}$ Z-score (aka, a standard score) indicates how many standard deviations an element is from the mean.

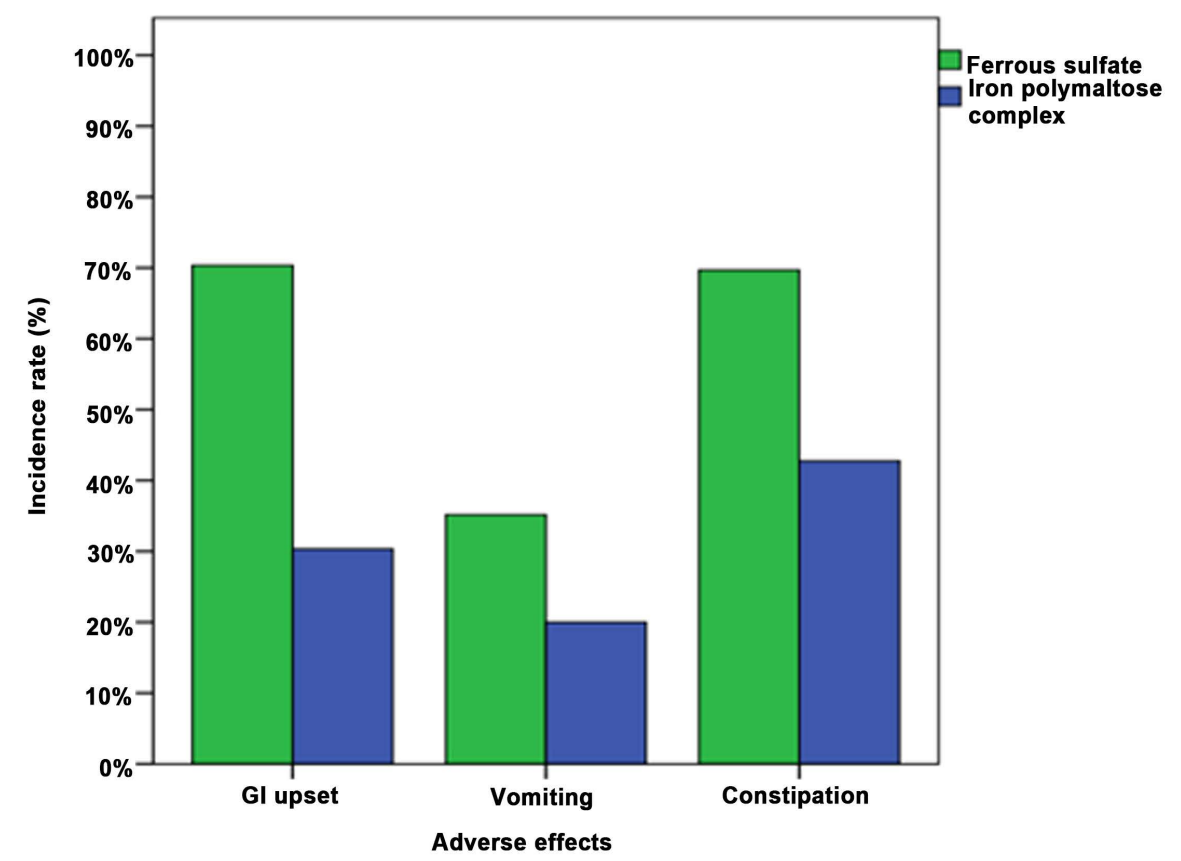

Figure 3. Incidence of adverse effects in both study groups. 


\section{Discussion}

An increase in loss along with inadequate intake can lead to depletion of body iron stores, iron deficiency, and eventually to anemia. Iron requirements are increased during infancy, puberty, pregnancy, lactation and during menstruation [6]. The WHO estimates that $58 \%$ of pregnant women in developing countries are anemic mainly because of iron deficiency. The most common iron salt used for oral administration is ferrous sulfate, it is known to produce intestinal side effects (nausea, vomiting, constipation, bloating) in many users. There is a substantial amount of evidence showing that maternal iron deficiency anemia early in pregnancy can result in low birth weight subsequent to preterm delivery [7]. An association between maternal anemia and lower infant Apgar score was reported in some studies. Iron supplements improve the iron status of the mother during pregnancy and during the postpartum period, even in women who become pregnant with reasonable iron stores [8]. The most widely recommended oral iron is ferrous salts; however, the use of these salts is limited by low and variable absorption, chelation by food products, and free radical-mediated mucosal luminal damage [9]. The most common iron salt used for oral administration is ferrous sulfate, it is known to produce intestinal side effects (nausea, vomiting, constipation, bloating) in many users. Iron salts like ferrous sulfate, ferrous fumarate and ferrous gluconate are extensively prescribed for the prevention and treatment of iron deficiency. Relatively high concentrations of elemental iron are present in ferrous fumarate, with each $190 \mathrm{mg}$ of ferrous sulfate containing 60 mg of elemental iron [10]. Iron Polymaltose Complex (IPC), a combination of ferric iron with maltol (a food additive), was developed as a molecule that is soluble at neutral $\mathrm{pH}$ and is not chelated by other substances. Whenever IPC has been compared with a classical iron salt, the incidence, and often the severity of adverse events was either similar or lower than that observed with ferrous salts. This lower incidence and milder grade were particularly evident for nausea, vomiting, and heartburn, whereas the difference was not as apparent for diarrhea, although this was a relatively rare event for all treatments [11]. In this study, each group had received their allocated drug continuously for 8 weeks, as follows; group A (control group): received oral ferrous sulfate with folic acid (Ferrofol), group B: received oral iron polymaltose complex with folic acid (Ferose-F). The results of this study revealed that there was no significant difference between group A and group B regarding level of hemoglobin at 0 wk and at 4 wks $(P>0.05)$ while there was significant increase in the level of hemoglobin in group $B$ than group $A$ at 8 weeks $(P<0.01)$. There was significant increase in the level of hemoglobin in group A at 4 weeks of $(1.1 \mathrm{gm} / \mathrm{dl}),(12.6 \%$ of base line), and also at 8 weeks of $(2.0 \mathrm{gm} / \mathrm{dl}),(22.2 \%$ of base line), while in group B there was also a significant increase in the level of hemoglobin of $(1.1 \mathrm{gm} / \mathrm{dl}),(14.3 \%$ of base line), at 4 weeks and also at 8 weeks of $(2.1 \mathrm{gm} / \mathrm{dl}),(24.9 \%$ of base line), which shows that the rate of hemoglobin rise was higher in group B than group A. There was no significant difference between group A and group B regarding 
serum ferritin level at 0,4 , and 8 weeks $(\mathrm{P}>0.05)$. There was significant difference between group A and group $B$ regarding the incidence of adverse effects of course of treatment including constipation, GI upset and vomiting $(\mathrm{P}<0.01)$. The incidence of side effects showed great difference between both groups, such as GI upset: 102 patients (70.3\%) In-group A, 44 patients (30.3\%) in-group B, constipation: 101 patients (69.7\%) in-group A, 62 patients (42.8\%) In-group B and vomiting: 51 patients (35.2\%) in-group A, 29 patients (20.0\%) in-group B. In agreement with this study, Ricardo [12]; mclad conducted an open-label, randomized, controlled, multicenter study to evaluate the efficacy and safety of iron (III) polymaltose complex versus ferrous sulfate in 80 iron-deficient pregnant women using recommended doses for 90 days. Result showed change in hemoglobin from baseline to days 60 and 90, did not differ significantly between treatment groups. In addition, mean serum ferritin at day 90 was 179 (38) $\mathrm{ng} / \mathrm{mL}$ and 157 (34) $\mathrm{ng} / \mathrm{mL}$ with iron (III) polymaltose complex and ferrous sulfate, respectively $(\mathrm{p}=0.014)$. Adverse events were significantly less frequent in the iron (III) polymaltose group, occurring in 12/41 (29.3\%) patients, than in the ferrous sulfate group $(22 / 39$ [56.4\%]) $(\mathrm{p}=0.015)$. Regarding combination of iron with folic acid in treatment of iron deficiency anemia with pregnancy, Juarez-Vazquez [13] had conducted a Multicenter, double blind, randomized clinical trial study to evaluate whether folate supplementation to iron is able to accelerate solving of iron deficiency anemia in 371 pregnant women. His study showed that Combined iron and folate therapy showed a better therapeutic response: the increase in hemoglobin levels from baseline was $1.42(0.14) \mathrm{g} / \mathrm{dL}$ for women treated with both compounds vs $0.80(0.125) \mathrm{g} / \mathrm{dL}$ for those given iron only $(\mathrm{P}<0.001)$. A multivariable regression analysis showed that this effect was independent of basal levels of blood iron, ferritin and serum folate and was more evident in women with more severe anemia. No significant differences in tolerability were observed between the two groups. In contrast to this study, Khalafallah [14] had conducted a prospective, nonblinded randomized-controlled trial to compare the efficacy, safety, tolerability and compliance of standard oral daily iron versus intravenous iron in 2654 pregnant women of which 461 (18\%) had moderate iron deficiency anemia. 200 women matched form hemoglobin concentration and serum ferritin level were recruited. Patients were randomized to daily oral ferrous sulfate $250 \mathrm{mg}$ (elementaliron $80 \mathrm{mg}$ ) with or without a single intravenous iron polymaltose infusion. Prior to delivery, the intravenous plus oral iron arm was superior to the oral iron only arm as measured by the increase in hemoglobin level (mean of $19.5 \mathrm{~g} / \mathrm{Lvs.} 12 \mathrm{~g} / \mathrm{L} ; \mathrm{P}<0.001$ ); the increase in mean serum ferritin level (222 lg/Lvs. $18 \mathrm{ug} / \mathrm{L} ; \mathrm{P}<0.001)$; and the percentage of mothers with ferritin levels below $30 \mathrm{lg} / \mathrm{L}(4.5 \%$ vs. $79 \%$; $\mathrm{P}<0.001)$. A single dose of intravenous iron polymaltose was well tolerated without significant side effects. Makrides [15] had conducted a double blind, randomized-controlled trial study to assess the effect on maternal iron deficiency anemia and iron deficiency (without anemia) of supplementing pregnant women with a low dosage $(20 \mathrm{mg} / \mathrm{d})$ of 
iron. Effects on iron status were assessed at the time of delivery and at 6 months postpartum. Results showed 430 women were enrolled, and 386 (89.7\%) completed the follow-up to 6 months postpartum. At delivery, fewer women from the iron-supplemented group than from the placebo group had iron deficiency anemia [6/198, or $3 \%$, compared with $20 / 185$, or $11 \%$; relative risk (RR): 0.28 ; $95 \%$ CI: $0.12,0.68 ; \mathrm{P}<0.005]$, and fewer women from the iron-supplemented group had ID (65/186, or $35 \%$, compared with $102 / 176$, or $58 \%$; RR: 0.60 ; $95 \%$ CI: $0.48,0.76 ; \mathrm{P}<0.001)$. There was no significant difference in gastrointestinal side effects between groups. The rate of iron deficiency between the groups did not differ significantly at 6 months postpartum.

\section{Conclusion}

The results of the study showed that oral iron polymaltose complex increases Hemoglobin and serum ferritin levels more than oral ferrous sulfate and produces less adverse effects than ferrous sulfate.

\section{Conflicts of Interest}

The authors declare no conflicts of interest regarding the publication of this paper.

\section{References}

[1] World Health Organization (2001) Iron Deficiency Anemia, Assessment, Prevention, and Control: A Guide for Program Managers.

[2] Dusch, E. and Elder, L. (2002) Women's Perceptions of Iron Deficiency and Anemia Prevention and Control in Eight Developing Countries. Social Science \& Medicine, 55, 529-544. https://doi.org/10.1016/S0277-9536(01)00185-X

[3] Adamson, J.W. (2001) Iron Deficiency and Other Hypo Proliferative Anemias. In: Harrison's Principles of Internal Medicine, 15th Edition, McGraw Hill, 660-666.

[4] Hurrell, R.F., Furniss, D.C. and Burri, J. (1989) Iron Fortification of Infant Cereals: A Proposal for Use of Ferrous Fumerate or Succinate. The American Journal of Clinical Nutrition, 49, 1274-1282. https://doi.org/10.1093/ajcn/49.6.1274

[5] Jacobs, P., Wormald, L.A. and Gregory, M.C. (1979) Absorption of Iron Polymaltose and Ferrous Sulphate in Rats and Humans-A Comparative Study. South African Medical Journal, 26, 1065-1072.

[6] Sharma, J.B. (2003) Nutritional Anemia during Pregnancy in Non-Industrialised Countries. In: Studd, J., Ed., Progress in Obstetrics and Gynecology, Churchill Livingstone, New Delhi, 103-122.

[7] Klebanoff, M.A., Shiono, P.H. and Selby, J.V. (1991) Anemia and Spontaneous Preterm Birth. American Journal of Obstetrics \& Gynecology, 164, 59-63. https://doi.org/10.1016/0002-9378(91)90626-3

[8] Allen, L.H. (2000) Anemia and Iron Deficiency: Effects on Pregnancy Outcome. The American Journal of Clinical Nutrition, 71, 1280-1284. https://doi.org/10.1093/ajcn/71.5.1280s

[9] Jacobs, P., Johnson, G. and Wood, L. (1984) Oral Iron Therapy in Human Subjects, Comparative Absorption between Ferrous Salts and Iron Polymaltose. Journal of Medicine, 15, 367-377. 
[10] Frewin, R., Henson, A. and Provan, D. (1997) ABC of Clinical Haematology: Iron Deficiency Anemia. BMJ, 314, 360-363. https://doi.org/10.1136/bmj.314.7077.360

[11] Mills, K.C. and Curry, S.C. (1994) Acute Iron Poisoning. Emergency Medicine Clinics of North America, 12, 397-413.

[12] Ortiz, R., Toblli, J.E., Romero, J.D., Monterrosa, B., Frer, C., Macagno, E. and Breymann, C. (2011) Efficacy and Safety of Oral Iron(III) Polymaltose Complex versus Ferrous Sulfate in Pregnant Women with Iron-Deficiency Anemia: A Multicenter, Randomized, Controlled Study. The Journal of Maternal-Fetal \& Neonatal Medicine, 24, 1347-1352. https://doi.org/10.3109/14767058.2011.599080

[13] Juarez-Vazquez, J., Bonizzoni, E. and Scotti, A. (2002) Iron Plusfolate Is More Effective than Iron Alone in the Treatment of Iron Deficiency Anemia in Pregnancy: A Randomized, Double Blind Clinical Trial. BJOG, 109, 1009-1014. https://doi.org/10.1111/j.1471-0528.2002.01378.x

[14] Khalafallah, A., Dennis, A., Bates, J., Bates, G., Robertson, I.K., Smith, L., Ball, M.J., Seaton, D., Brain, T. and Rasko, J.E. (2010) Intravenous versus Oral Iron for Moderate Iron Deficiency Anemia of Pregnancy. Journal of Internal Medicine, 268, 286-295.

[15] Makrides, M., Crowther, C.A., Gibson, R.A., Gibson, R.S. and Skeaff, C.M. (2003) Efficacy and Tolerability of Low-Dose Iron Supplements during Pregnancy: A Randomized Controlled Trial. The American Journal of Clinical Nutrition, 78, 145-153. https://doi.org/10.1093/ajcn/78.1.145 